\title{
Serological and molecular detection of spotted fever group Rickettsia in a group of pet dogs from Luanda, Angola
}

\author{
Patrícia F. Barradas ${ }^{1}$, Hugo Vilhena ${ }^{2,3,4}$, Ana Cristina Oliveira ${ }^{5}$, Sara Granada ${ }^{5}$, Irina Amorim ${ }^{1,6,7}$, Paula Ferreira ${ }^{1,6,8}$, \\ Luís Cardoso $^{9^{*}}$ (D) Fátima Gärtner ${ }^{1,6,7}$ and Rita de Sousa ${ }^{10}$
}

\begin{abstract}
Background: Infections with tick-borne rickettsiae can cause diseases well known in humans but still not so well characterized in dogs. Susceptibility to infection depends on the virulence of Rickettsia spp. and only a few of them have been described to cause disease in dogs. The aim of this study was to investigate the exposure to Rickettsia spp. among a group of pet dogs from Luanda, Angola.

Results: Out of 103 dogs included in the study, 62 (60.2\%) were infested with ticks. Plasma specimens tested for serology by an immunofluorescence assay (IFA) revealed that six (5.8\%) dogs had detectable immunoglobulin $\mathrm{G}$ (IgG) antibodies to spotted fever group Rickettsia (SFGR), with endpoint titers of 64 for two dogs, 128 for three dogs and 1024 for one dog. From the seropositive group of dogs, five (83\%) of them were males, with their age ranging from 1 to 8 years old. Among the seropositive dogs, four (66.7\%) were parasitized with ticks and no breed (or cross) was found to be associated with specific antibodies. Rickettsia spp. DNA was detected by nested-polymerase chain reaction (PCR) in two (1.9\%) dogs that were found to be seronegative.

Conclusions: Seroprevalence and molecular detection of Rickettsia spp. infection in this group of pet dogs from Luanda is low compared with other studies performed in the same type of hosts in other areas. Although many dogs were parasitized with ticks, a low prevalence of Rickettsia spp. could be related with the hypothesis of a low rickettsial prevalence in the infesting ticks. This study provides evidence that dogs in Luanda are exposed to Rickettsia spp., but further studies are needed to better characterize the bacterial infections in dogs and in their ectoparasites.
\end{abstract}

Keywords: Angola, Dogs, Rickettsia, Seroprevalence, Spotted fever group

\section{Background}

Canine vector-borne diseases (CVBD) are currently a focus of increasing attention, due to their clinical importance in veterinary medicine and also in public health [1]. The agents that cause CVBD are transmitted by hematophagous arthropods such as ticks, fleas and mosquitoes [2]. Dogs are hosts for these ectoparasites, allowing them to feed on blood in order to complete their life-cycle. When infected, these ectoparasites may transmit the pathogens to dogs, which in turn may

\footnotetext{
* Correspondence: Icardoso@utad.pt

${ }^{9}$ Department of Veterinary Sciences, School of Agrarian and Veterinary

Sciences, UTAD, Vila Real, Portugal

Full list of author information is available at the end of the article
}

develop clinical manifestations or remain apparently healthy although infected, but potentially acting as a reservoir for those agents [3].

Tick-borne rickettsiae are well known to cause disease in humans, but knowledge on the susceptibility of dogs to different Rickettsia spp. and related illnesses is still limited. Dogs can develop transient rickettsiemia and show clinical signs; however, they are not considered reservoirs of Rickettsia spp. [4]. Since dogs are often exposed to infected ectoparasites, they develop antibodies against these agents and can be used as sentinels, i.e. to reveal the presence of pathogens that are circulating in a particular geographical region [5-7]. Nevertheless, due to cross-reactivity, serology does not allow the discrimination of Rickettsia spp. 
within the spotted fever group (SFGR) or typhus group rickettsiae (TGR). Under this circumstance, molecular detection and sequencing are the methods that enable Rickettsia spp. identification $[6,8,9]$.

Up until now, only Rickettsia rickettsii $[10,11]$ and Rickettsia conorii $[6,12]$ have been described to cause diseases in dogs. In Africa, SFGR has been detected in ticks and human patients [13], but only a few studies have been carried out in dogs [14]. To better understand if rickettsiae are circulating in dogs in Luanda, this study aimed to evaluate the seroprevalence and to characterize Rickettsia spp., using molecular tools, in a convenience sample of dogs from Luanda.

\section{Methods}

\section{Dogs}

From January to February of 2013, a total of 103 pet dogs presented to a veterinary clinic in Luanda city, Angola were included in this study. Dogs were targeted by convenience sampling and comprised two groups: (i) apparently healthy animals that were brought in for prophylactic procedures, including vaccination or deworming; and (ii) dogs with a clinical suspicion of CVBD, presenting with at least one of the following clinical manifestations: anorexia, weight loss, fever, dehydration, onychogryphosis, lymphadenomegaly, gastrointestinal alterations, jaundice, dermatological or ocular abnormalities, anemia, thrombocytopenia, leukocytosis or leukopenia, hyperproteinemia or hyperglobulinemia.

For all the dogs included in the study, a questionnaire with epidemiological, clinical and laboratory data was completed. EDTA-anticoagulated whole blood specimens were collected from each dog. Blood specimens were centrifuged and plasma and buffy-coat were separated and stored at $-20{ }^{\circ} \mathrm{C}$.

\section{Serological analysis}

IgG antibodies against Rickettsia spp. were detected by an in-house IFA using a Rickettsia africae strain as antigen, prepared at the Portuguese National Institute of Health, as previously described [15]. The cut-off for a positive result was considered at a titre of $\operatorname{IgG} \geq 128$, and a titer of 64 was considered suspected of contact, based on previous studies in Portuguese dogs [5].

\section{Molecular analysis}

Total genomic DNA was extracted from $400 \mu \mathrm{l}$ of peripheral mononuclear cells (buffy-coat) using a commercial kit (E.Z.N.A. ${ }^{\circ}$ Blood DNA Mini Kit, Omega Bio-Tek, Norcross, GA, USA), according to the manufacturer's instructions.

Rickettsia DNA in blood was screened by nestedpolymerase chain reaction (PCR) targeting a fragment of the outer membrane protein $\mathrm{B}(O m p \mathrm{~B})$ gene, as previously described by Choi et al. [16]. The first PCR reaction was performed using the set of primers Romp $\mathrm{B}$ OF and RompB OR, which amplify a 511 bp fragment, and was followed by a second PCR reaction with internal set of primers of RompB SFG-IF and RompB SFG-IR, which amplify a $420 \mathrm{bp}$ fragment [16]. For each reaction, water and $R$. rickettsii were included as negative and positive controls, respectively.

The PCR products of the expected size were purified with ExoSAP-IT PCR Product Cleanup (Affymetrix, Santa Clara, CA, USA) and were sequenced with the Big-Dye Terminator Cycle Sequencing kit (Applied Biosystems, Foster City, CA, USA) on an ABI 377 DNA sequencer according to the manufacturer's recommendations. The sequencing reactions were performed with the forward and reverse primers used for PCR amplification. The sequences were analysed with Lasergene software v.7.0.

\section{Results}

Out of the 103 tested dogs, 61 were males. Ages ranged from 3 to 168 months old (median: 12 months; interquartile range: 7.3-48). Eighty (77.7\%) were outdoorliving dogs and $62(60.2 \%)$ were infested with ticks. Based on physical and clinicopathological examination, $49(47.6 \%)$ dogs were classified as apparently healthy and $54(52.4 \%)$ dogs as clinically suspected of a CVBD.

SFGR-specific IgG antibodies were detected in six (5.8\%) dogs, comprising two suspected dogs (i.e. with an endpoint titer of 64) and four positive dogs (three dogs with an endpoint of 128 and one dog with 1024).

From the seropositive group of dogs, five $(83 \%)$ were males, with ages ranging from 1 to 8 years old, and all lived outdoors. Four (66.7\%) of the six dogs with detectable antibodies were parasitized by ticks and no breed (or cross) was found to be associated with the presence of antibodies. Differential diagnostic showed that four (66.7\%) of the dogs with antibodies to Rickettsia spp. were co-infected with single or multiple pathogens (molecular data not shown), such as Anaplasma platys [17], Hepatozoon canis [17], Leishmania infantum [18] or Toxoplasma gondii [19].

Rickettsia DNA was detected in two (1.9\%) dogs, but sequence analysis was not able to identify species. One of these two dogs presented clinical manifestations compatible with CVBD, namely fever and anemia. None of those two dogs was seropositive for Rickettsia spp. by IFA. The clinically suspected dog was co-infected with Babesia spp. (molecular data not shown) [17].

\section{Discussion}

To the best of our knowledge, this study shows for the first time the presence of SFGR in dogs in Luanda. A considerably lower prevalence of IgG antibodies against Rickettsia spp. was found in dogs when compared with other studies that assessed serum samples from dogs 
[11] or people [16]. On the other hand, the molecular prevalence in the present study was also lower than in another study that assessed Rickettsia spp. in dogs from Nigeria [12]. Nevertheless, the low prevalence could be related to the fact that tick species that were infesting this group of dogs had a low prevalence of rickettsial infection. For example, it has been described that Amblyomma spp. ticks, regarded as the vector of $R$. africae, are rarely found parasitizing dogs [20-23]. Other studies performed in Africa have revealed a high prevalence of Rickettsia spp. in dogs [24], as well as a high prevalence of pathogenic rickettsiae in ticks collected from domestic animals and cattle from Benin [22], Kenya [23] and Nigeria [25]. In North Africa the prevalence of infection in ticks matches that from southern Europe [24, 26-28], whereas in sub-Saharan Africa their prevalence is even higher, a situation which seems to be related with the distribution of Amblyomma spp. ticks [29]. One limitation of this study was the fact that it was not possible to identify the tick species that were infesting dogs. If they were infected with Rickettsia spp., additional data could help to explain the low prevalence of antibodies found in this group of dogs.

Seroepidemiological studies have used dogs and other canids as sentinels for the presence of Rickettsia spp. infection [5, 30]; however, and since serological crossreactions within SFGR do not allow species differentiation, we have used molecular tools to characterize the Rickettsia spp. that could be circulating in the blood of dogs and could be associated with clinical illness $[6,9]$. Nevertheless, in two dogs positive to Rickettsia DNA it was not possible to have a good quality of sequences to characterize Rickettsia spp. The positive PCR results in dogs without antibodies are concordant with what we found in humans [31]. In general, during an acute infection, when it is possible to detect rickettsiae DNA in blood, the host had not enough time to produce antibodies [32]. Most of the dogs are exposed during their lifetime to multiple pathogens to which they develop antibodies and it is very difficult to conclude about the canine rickettsial diseases based only in one testing sample. Testing two consecutive samples with 2-week intervals is advisable to detect seroconversion. Molecular detection for differential diagnosis is also very useful to distinguish CVBD agents. In this same group of dogs from Luanda, Cardoso et al. [17] by PCR identified five distinct tickborne pathogens, A. platys (17.5\%), Ehrlichia canis and $H$. canis (5.8\%, each), Babesia vogeli (1.0\%), Babesia gibsoni and an unnamed Babesia sp. (1.0\%). Other two studies done with the same group of dogs detected the presence of $L$. infantum (1.9\% by serology and $1.0 \%$ by PCR) [18] and of T. gondii (seroprevalence of 15.5\%) [19].

New studies are needed to better characterize the circulation of Rickettsia spp. in vertebrate hosts and vectors in Angola, in order to try and understand their epidemiology and clinical importance in domestic and freeroaming dogs.

\section{Conclusions}

To the best of our knowledge, this is the first study that provides evidence for the presence of Rickettsia spp. in a canine population from Luanda, Angola. Further investigations, including a larger population of domestic and free-roaming dogs from different urban and rural provinces of Angola and vectors of Rickettsia spp., are necessary to better understand the epidemiology and clinical importance of these vector-borne agents.

\section{Abbreviations}

CVBD: Canine vector-borne diseases; IFA: Immunofluorescence assay; IgG: Immunoglobulin G; PCR: Polymerase chain reaction; SFGR: Spotted fever group Rickettsia

\section{Acknowledgements}

The publication of this paper has been sponsored by Bayer Animal Health in the framework of the 12th CVBD World Forum Symposium. IPATIMUP integrates the i3S Research Unit, which is partially supported by FEDER through the Operational Programme for Competitiveness Factors-COMPETE and National Funds through the Portuguese Foundation for Science and Technology (FCT), under the project number PEst-C/SAU/LA0003/2013.

Funding

Not applicable.

Availability of data and materials

The datasets used and/or analyzed during the current study are available from the corresponding author on request.

\section{Authors' contributions \\ Designed the study: PFB, FG and RdS; performed clinical examination and sample collection: $\mathrm{AO}, \mathrm{SG}$ and $\mathrm{HV}$; processed samples and extracted DNA: PFB, HV, LC and RdS; performed IFA, PCR and sequencing: PFB and RdS; analysed data and wrote the manuscript: PFB, LC and RdS; reviewed the manuscript: IA, PF and FG. All authors read and approved the final manuscript.}

\section{Competing interests}

The authors declare that they have no competing interests.

\section{Consent for publication}

Not applicable.

Ethics approval and consent to participate

Informed consent was obtained from all the owners. This study was approved by the scientific council of Escola Universitária Vasco da Gama, Coimbra, Portugal, as complying with the Portuguese legislation for the protection of animals (Law no. 92/1995 and Decree-Law no. 113/2013).

\section{Publisher's Note}

Springer Nature remains neutral with regard to jurisdictional claims in published maps and institutional affiliations.

\section{Author details}

${ }^{1}$ Institute of Biomedical Sciences Abel Salazar (ICBAS), University of Porto, Oporto, Portugal. ${ }^{2}$ Animal and Veterinary Research Centre (CECAV), University of Trás-os-Montes e Alto Douro (UTAD), Vila Real, Portugal. ${ }^{3}$ Department of Veterinary Medicine, Escola Universitária Vasco da Gama, Coimbra, Portugal. ${ }^{4}$ Baixo Vouga Veterinary Hospital, Águeda, Portugal. ${ }^{5}$ Casa dos Animais

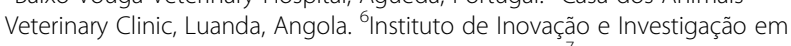
Saúde (i3S), Universidade do Porto, Oporto, Portugal. ${ }^{7}$ Institute of Molecular Pathology and Immunology of the University of Porto (IPATIMUP), Oporto, 
Portugal. ${ }^{8}$ Instituto de Biologia Molecular e Celular (IBMC), Universidade do Porto, Oporto, Portugal. ${ }^{9}$ Department of Veterinary Sciences, School of Agrarian and Veterinary Sciences, UTAD, Vila Real, Portugal. ${ }^{10}$ National Institute of Health Dr. Ricardo Jorge (INSA), Lisbon, Portugal.

\section{Received: 21 March 2017 Accepted: 24 May 2017}

\section{Published online: 31 May 2017}

\section{References}

1. Mencke N. Future challenges for parasitology: vector control and 'One health' in Europe: the veterinary medicinal view on CVBDs such as tick borreliosis, rickettsiosis and canine leishmaniosis. Vet Parasitol. 2013;195:256-71.

2. Beugnet F, Marie JL. Emerging arthropod-borne diseases of companion animals in Europe. Vet Parasitol. 2009;163:298-305.

3. Movilla R, García C, Siebert S, Roura X. Countrywide serological evaluation of canine prevalence for Anaplasma spp., Borrelia burgdorferi (sensu lato), Dirofilaria immitis and Ehrlichia canis in Mexico. Parasit Vectors. 2016;9:421.

4. Levin ML, Zemtsova GE, Montgomery M, Killmaster LF. Effects of homologous and heterologous immunization on the reservoir competence of domestic dogs for Rickettsia conorii (israelensis). Ticks Tick Borne Dis. 2014; 5:33-40.

5. Bacellar F, Dawson JE, Silveira CA, Filipe AR. Antibodies against Rickettsiaceae in dogs of Setubal. Portugal Cent Eur J Public Health. 1995;3: $100-2$.

6. Alexandre N, Santos AS, Bacellar F, Boinas FJ, Nuncio MS, de Sousa R. Detection of Rickettsia conorii strains in Portuguese dogs (Canis familiaris). Ticks Tick Borne Dis. 2011;2:119-22.

7. Solano-Gallego L, Llull J, Osso M, Hegarty B, Breitschwerdt E. A serological study of exposure to arthropod-borne pathogens in dogs from northeastern Spain. Vet Res. 2006:37:231-44.

8. Solano-Gallego L, Trotta M, Caldin M, Furlanello T. Molecular survey of Rickettsia spp. in sick dogs in Italy. Zoonoses Public Health. 2008:55:521-5.

9. Solano-Gallego L, Capri A, Pennisi MG, Caldin M, Furlanello T, Trotta M. Acute febrile illness is associated with Rickettsia spp infection in dogs. Parasit Vectors. 2015;8:216.

10. Labruna MB, Kamakura O, Moraes-Filho J, Horta MC, Pacheco RC. Rocky Mountain spotted fever in dogs. Brazil Emerg Infect Dis. 2009;15:458-60.

11. Paddock CD, Brenner O, Vaid C, Boyd DB, Berg JM, Joseph RJ, et al. Short report: concurrent Rocky Mountain spotted fever in a dog and its owner. Am J Trop Med Hyg. 2002;66:197-9.

12. Solano-Gallego L, Kidd L, Trotta M, Di Marco M, Caldin M, Furlanello T, et al. Febrile illness associated with Rickettsia conorii infection in dogs from Sicily. Emerg Infect Dis. 2006;12:1985-8.

13. Parola P. Rickettsioses in sub-Saharan Africa. Ann NY Acad Sci. 2006;1078: 42-7.

14. Proboste T, Kalema-Zikusoka G, Altet L, Solano-Gallego L. Fernandez de Mera IG, Chirife AD, et al. Infection and exposure to vector-borne pathogens in rural dogs and their ticks, Uganda. Parasit Vectors. 2015;8:306.

15. Bacellar F, Sousa R, Santos A, Santos-Silva M, Parola P. Boutonneuse fever in Portugal: 1995-2000. Data of a state laboratory. Eur J Epidemiol. 2003;18: 275-7.

16. Choi YJ, Lee SH, Park KH, Koh YS, Lee KH, Baik HS, et al. Evaluation of PCRbased assay for diagnosis of spotted fever group rickettsiosis in human serum samples. Clin Diagn Lab Immunol. 2005;12:759-63.

17. Cardoso L, Oliveira AC, Granada S, Nachum-Biala Y, Gilad M, Lopes AP, et al. Molecular investigation of tick-borne pathogens in dogs from Luanda. Angola. Parasit Vectors. 2016;9:252.

18. Vilhena H, Granada S, Oliveira AC, Schallig HD, Nachum-Biala Y, Cardoso L, et al. Serological and molecular survey of Leishmania infection in dogs from Luanda. Angola Parasit Vectors. 2014;7:114

19. Lopes AP, Granada S, Oliveira AC, Brancal H, Dubey JP, Cardoso L, et al. Toxoplasmosis in dogs: first report of Toxoplasma gondii infection in any animal species in Angola. Pathog Glob Health. 2014;108:344-6.

20. Socolovschi C, Huynh TP, Davoust B, Gomez J, Raoult D, Parola P. Transovarial and trans-stadial transmission of Rickettsiae africae in Amblyomma variegatum ticks. Clin Microbiol Infect. 2009;15(Suppl 2):317-8.

21. Brouqui P, Harle JR, Delmont J, Frances C, Weiller PJ, Raoult D. African tickbite fever. An imported spotless rickettsiosis. Arch Intern Med. 1997;157:119-24.
22. Morita C, El Hussein AR, Matsuda E, Abdel Gabbar KM, Muramatsu Y, Abdel Rahman MB, et al. Spotted fever group rickettsiae from ticks captured in Sudan. Jpn J Infect Dis. 2004;57:107-9.

23. Nakao R, Qiu Y, Salim B, Hassan SM, Sugimoto C. Molecular detection of Rickettsia africae in Amblyomma variegatum collected from Sudan. Vector Borne Zoonotic Dis. 2015;15:323-5.

24. Bessas A, Leulmi H, Bitam I, Zaidi S, Ait-Oudhia K, Raoult D, et al. Molecular evidence of vector-borne pathogens in dogs and cats and their ectoparasites in Algiers. Algeria Comp Immunol Microbiol Infect Dis. 2016; 45:23-8.

25. Ogo NI, de Mera IG, Galindo RC, Okubanjo OO, Inuwa HM, Agbede RI, et al. Molecular identification of tick-borne pathogens in Nigerian ticks. Vet Parasitol. 2012;187:572-7.

26. Leulmi H, Aouadi A, Bitam I, Bessas A, Benakhla A, Raoult D, et al. Detection of Bartonella tamiae, Coxiella burnetii and rickettsiae in arthropods and tissues from wild and domestic animals in northeastern Algeria. Parasit Vectors. 2016;9:27.

27. Abdel-Shafy S, Allam NA, Mediannikov O, Parola P, Raoult D. Molecular detection of spotted fever group rickettsiae associated with ixodid ticks in Egypt. Vector Borne Zoonotic Dis. 2012;12:346-59.

28. Oteo JA, Portillo A. Tick-borne rickettsioses in Europe. Ticks Tick Borne Dis. 2012;3:271-8.

29. Dupont HT, Brouqui P, Faugere B, Raoult D. Prevalence of antibodies to Coxiella burnetti, Rickettsia conorii, and Rickettsia typhi in seven African countries. Clin Infect Dis. 1995;21:1126-33.

30. Harrus S, Lior Y, Ephros M, Grisaru-Soen G, Keysary A, Strenger C, et al, Rickettsia conorii in humans and dogs: a seroepidemiologic survey of two rural villages in Israel. AmJTrop Med Hyg. 2007;77:133-5.

31. Sousa R, Franca A, Doria Nobrega S, Belo A, Amaro M, Abreu T, et al. Hostand microbe-related risk factors for and pathophysiology of fatal Rickettsia conorii infection in Portuguese patients. J Infect Dis. 2008;198:576-85.

32. Kidd L, Maggi R, Diniz PPVP, Hegarty B, Tucker M, Breitschwerdt E. Evaluation of conventional and real-time PCR assays for detection and differentiation of Spotted Fever Group Rickettsia in dog blood. Vet Microbiol. 2008:129:294-303.

\section{Submit your next manuscript to BioMed Central and we will help you at every step:}

- We accept pre-submission inquiries

- Our selector tool helps you to find the most relevant journal

- We provide round the clock customer support

- Convenient online submission

- Thorough peer review

- Inclusion in PubMed and all major indexing services

- Maximum visibility for your research

Submit your manuscript at www.biomedcentral.com/submit
Biomed Central 